\title{
Endometrial Hyperplasia: Epidemiological Profile of Patients and Anatomical and Clinical Aspects of Lesions at Conakry University Hospital
}

\author{
M. C. Diallo ${ }^{*}$, E. M. Bah ${ }^{2}$, B. A. Diallo², I. K. Bah ${ }^{2}$, A. Diallo', O. Baldé ${ }^{2}$, A. Sylla ${ }^{3}$, A. Baldé1, \\ I. S. Baldé ${ }^{1}$, A. B. Diallo ${ }^{1}$ \\ ${ }^{1}$ Obstetrical Gynecology Department, Gamal Abdel Nasser University, Conakry, Guinea \\ ${ }^{2}$ Donka Obstetrical Gynecology Department, Gamal Abdel Nasser University, Conakry, Guinea \\ ${ }^{3}$ Donka Anatomy and Pathological Cytology Department, Gamal Abdel Nasser University, Conakry, Guinea \\ Email: *celloudiallo69@yahoo.fr, ^belhadjmamoudou70@gmail.com
}

How to cite this paper: Diallo, M.C., Bah, E.M., Diallo, B.A., Bah, I.K., Diallo, A., Baldé, O., Sylla, A., Baldé, A., Baldé, I.S. and Diallo, A.B. (2019) Endometrial Hyperplasia: Epidemiological Profile of Patients and Anatomical and Clinical Aspects of Lesions at Conakry University Hospital. Open Journal of Obstetrics and Gynecology, 9, 260-266.

https://doi.org/10.4236/ojog.2019.92027

Received: December 26, 2018

Accepted: February 23, 2019

Published: February 26, 2019

Copyright $\odot 2019$ by author(s) and Scientific Research Publishing Inc. This work is licensed under the Creative Commons Attribution International License (CC BY 4.0).

http://creativecommons.org/licenses/by/4.0/

\begin{abstract}
Summary: Estimate the incidence of endometrial hyperplasia according to socio-demographic parameters and the type of lesions histological. Methodology: This was a retrospective, and 15-year descriptive study from January 1, 2000 to December 31, 2014 conducted at the Department of Anatomy and Pathological Cytology of the National Hospital Donka in collaboration with the obstetric gynecology departments of the Conakry University Hospital. Results: We collected 296 cases of malignant and benign endometrial hyperplasia in 15 years, accounting for $37 \%$ of all endometrial biopsy curettages examined. The age group 47 to 56 years was the most affected ( 81 cases) or $27,36 \%$. The mean age was 53.6 years with extremes of 27 and 83 years. Metrorrhagia was the main reason for consultation (206 cases), i.e. $69.59 \%$. The suspicion of endometrial hyperplasia by physicians was the most frequently diagnosed circumstance (149 cases) or 50.33\%. Biopsy curettage was the most frequently used method (176 cases), is $59.45 \%$. Histological endometrial lesions of atypical complex adenomatous hyperplasia (79 cases) represented $26.69 \%$. Benign behavior was most frequently observed in (235 cases) or $79.39 \%$. Conclusion: Endometrial hyperplasia is an endometrial lesion whose atypical histological types represent the borderline lesions between benignity and malignancy.
\end{abstract}

\section{Keywords}

Endometrial Hyperplasia, Epidemiology, Anatomoclinical, CHU Conakry 


\section{Introduction}

Endometrial hyperplasia is organic lesion characterized by an increase in the cellular mass of the endometrial glandular structures, which may be accompanied by architectural disorganization and cytonuclear atypia [1].

They are increasingly common, but their frequency is difficult to specify, as many of its types do not have histological evidence [2].

Atypical histological types are precancerous lesions, as they inexorably evolve towards cancerization [3]. They then pose a public health problem, due to their frequency and evolution. Their discovery requires further investigation to eliminate adenocarcinoma from the endometrium [4].

Nowadays, diagnostic and surgical hysteroscopy is the most popular technique for reliable diagnosis and appropriate management. Histology is the key examination; it is what allows the diagnosis of certainty of endometrial hyperplasia [5] [6].

According to WHO, their frequency was a function of the histological type: simple hyperplasia $55 \%$, complex hyperplasia $17 \%$, atypical simple hyperplasia $8 \%$, atypical complex hyperplasia $20 \%$ [7]. The problem of hyperplasia is their diagnosis. BERGERON et al. [8] reported in their series that the frequency of anatomopathological findings are as follows: $66.7 \%$ simple hyperplasia without atypia; $13 \%$ complex hyperplasia without atypia; $20 \%$ cellular atypia.

In Guinea, despite the existence of a University Hospital Centre, anatomopathological examinations are rarely carried out, even for obvious indications such as the presence of organic pathologies or unexplained non-functional metrorrhages. Objectives: Estimate the incidence of endometrial hyperplasia according to socio-demographic parameters and the type of lesions histological.

\section{Methodology}

This was a retrospective study, of a descriptive type covering a period of 15 years, from 1 January 2000 to 31 December 2014, carried out in the Anatomy and Pathological Cytology Department of the Donka National Hospital in collaboration with the Gynaecology and Obstetrics Department of the University Hospital of Conakry.

Included in this study were all cases of endometrial hyperplasia recorded in the service during the study period and excluded poorly maintained records and incomplete results.

The data were collected with the anatomopathological examination request forms, the sample registration registers, all the anatomopathological examination report forms containing endometrial sample results for the study period.

We noted the frequency, epidemiological profile of the patients, and histological type.

The collected data were entered with Excel software and analyzed with SPSS software version 16.0. 


\section{Results}

\section{Sociodemographic characteristics}

In this study 296 cases of benign and malignant endometrial hyperplasia were collected, representing $37 \%$ of all samples examined in the department. Benign endometrial hyperplasia was $80.40 \%$.

Socio-professional layers: Housewives were the most affected with 186 cases, or $62.83 \%$. They were followed by the liberal socio-professional strata with 66 cases, or $22.29 \%$.

Mini: 27 years old; Average: 53.6 years old; Max: 83 years old (Table 1).

Managed: Multi-gesture was the most affected with 14 cases, or $28.57 \%$. They were followed by the paucigest with 12 cases, or $24.48 \%$ (Table 2 and Table 3).

Table 1. Distribution of endometrial hyperplasia by age.

\begin{tabular}{ccc}
\hline Age & Number & Percentage \\
\hline $27-36$ years old & 29 & 9.80 \\
$37-46$ years old & 47 & 15.88 \\
$47-56$ years old & 81 & 27.36 \\
$57-66$ years old & 67 & 22.64 \\
$67-76$ years old & 60 & 20.27 \\
77 years and over & 12 & 4.05 \\
total & 296 & 100 \\
\hline
\end{tabular}

Table 2. Endometrial hyperplasia as a function of parity.

\begin{tabular}{ccc}
\hline Parity & Number of people & Percentage \\
\hline Nullipare (0 parity) & 37 & 12.5 \\
Primipare (1 parity) & 49 & 16.55 \\
Paucipare (2 - 3 parity) & 75 & 25.34 \\
Multipare (4 - 5 parity) & 64 & 21.62 \\
Large multipare (over 5 parity) & 71 & 23.99 \\
total & 296 & 100 \\
\hline
\end{tabular}

Table 3. Endometrial hyperplasia according to the sampling technique.

\begin{tabular}{ccc}
\hline Sampling technique & Number of people & Percentage \\
\hline Curettage biopsy & 176 & 59.46 \\
Biopsy under hysteroscopy & 6 & 2.03 \\
Subtotal hysterectomy & 24 & 8.10 \\
Total hysterectomy & 75 & 25.34 \\
Myomectomy & 15 & 5.07 \\
Total & 296 & 100 \\
\hline
\end{tabular}




\section{Anatomopathological aspect:}

Reasons for consultation: Metrorrhagia was the main reason for consultation with 206 cases, or $69.59 \%$, followed by abdominal pain, leucorrhea and dysmenorrhea with $12.16 \% ; 10.47 \%$ and $7.09 \%$ respectively.

Presumptive diagnosis: Endometrial hyperplasia was the most frequent with 149 cases, or $50.34 \%$, followed by malignant tumours with 61 cases, $20.61 \%$.

Sampling technique: Biopsy curettage was the most widely used technique, at $59.46 \%$.

Consistency: the consistency of the tissue sampled was more frequently firm with 163 samples or $55.06 \%$.

Histological types: Elemental histological lesions: Simple adenomatous hyperplasia was the most common elementary histological lesion encountered with 81 samples, or $27.36 \%$. It was followed by non-typical complex adenomatous hyperplasia complex 79 samples, or $26.68 \%$.

Histological behaviour: Hyperplasia with benign behaviour were the most frequently observed in 235 cases, or $79.39 \%$.

Associated heterogeneous lesions: In $73.98 \%$, there were no lesions associated with endometrial hyperplasia. In $12.84 \%$, hyperplasia was associated with leiomyomas and in $11.49 \%$, it was associated with adenomyosis.

\section{Discussion}

Frequency: Endometrial hyperplasia has occupied a prominent place among gynaecological pathologies. Our result was close to that of SAKANDE. B et al. in Burkina [9] who report that endometrial hyperplasia accounts for $20 \%$ of all endometrial biopsies performed. In Morocco for ZOUBIR [10] the frequency of endometrial hyperplasia is very difficult to specify, because the diagnosis is only made in symptomatic patients, whereas endometrial hyperplasia can be silent in $10 \%$ of cases. In the LEFRANC study, which included 200 histological examinations (100 biopsy curettages and 100 hysterectomies), the frequency of endometrial hyperplasia was $15.5 \%$ [7].

Sociodemographic characteristics: Risk factors for endometrial hyperplasia are related to a context of relative hyperestrogeny. This favourable hormonal terrain is found in anovulations or dysovulations (micro-polycystic ovary syndrome), obesity and secretory ovarian tumours. Our finding is thus consistent with the study by RIBEO C T et al. [11]. In the literature, the mean age of onset of endometrial hyperplasia is between 40 and 50 years depending on the authors [7] [8] [11]. According to the same authors, the average age is 51 years in the case of simple hyperplasia, and 56 years in the case of atypical hyperplasia. Normally, the cessation of ovarian activity in post-menopause explains the evolution towards atrophy of the endometrial mucosa. However, endometrial hyperplasia may persist in rare cases.

The predominance of housewives could be explained by the high number of patients from this socio-professional layer in our country where they represent more than $60 \%$ of women [12]. 
Contrary to our results, studies in the literature reveal a high frequency of endometrial hyperplasia in nulliparous women. The risk is sometimes multiplied by 2 for nulliparity: SAKANDE B. et al. report $35.8 \%$ of nulliparous cases and according to ZOUBIR [10], the relative risk was 1.4 for nulliparity. Among the risk factors, the following observations and data are found in the literature according to ZOUBIR [10]: endometrial adenomatous hyperplasia share the same risk factors with endometrial adenocarcinoma: obesity, nulliparity, hypertension, diabetes. Obesity is the most frequently cited risk factor, being present in $21 \%$ $83 \%$ of hyperplasia. The increased aromatization of androstenedione to estrone, particularly in fatty tissues, contributes to the increase in circulating estrogens in obese people. BRUN J. et al. [13] also found in a series of 97 patients followed for endometrial hyperplasia $23 \%$ obesity. Diabetes indirectly increases the frequency of hyperplasia through obesity. Pregnancy provides protection against endometrial hyperplasia and cancer by interrupting the continuous stimulation of the endometrium by estrogen.

Anatomoclinical aspects: The predominance of metrorrhagia is not surprising, as it is classically the dominant syndrome of benign and malignant endometrial lesions and this symptom has been reported as the main cause by various authors including [13] [14]. But endometrial hyperplasia can also be discovered by chance after a pelvic ultrasound or hysteroscopy for infertility assessment. Thus SAKANDE et al. [9] reported that patients consulted mainly for fertility disorders in $65.5 \%$ and for bleeding in $22.5 \%$. With regard to the diagnosis of presumption, there are no pathognomonic signs of endometrial hyperplasia. DARGENT [15] reported that the clinical examination is most often normal in case of endometrial hyperplasia, but it can show an enlarged uterus in case of association with uterine fibroids. According to the same author, $5 \%$ of the polyps visible at the cervix are endometrial.

Sampling technique: According to CATALA L. [16], endometrial sampling remains the rule in the presence of metrorrhagia. This sample can be obtained in different ways, by biopsy during a clinical examination, the most common technique in France being performed using a Cornier pipel, by endometrial curettage, by a directed sample during hysteroscopy.

A meta-analysis of DIJKHUIZEN et al. [17] involving 39 studies, including 7914 patients, compared histological results after biopsy, curettage and hysteroscopy. Sampling by the Cornier pipelay provides a sensitivity equivalent to the other two methods, in terms of cancer diagnosis and hyperplasia with atypia. The detection rate of endometrial cancer by pipel in postmenopausal and pre-menopausal women is respectively.

\section{Conclusions}

Endometrial hyperplasia is complex and heterogeneous organic lesion that poses a public health problem. Their general frequency is difficult to specify, as many of them are autopsy findings, not reported on the medical report and therefore not included in the statistics. 
Their problem is their late discovery because the symptoms and signs are not pathognomonic. The anatomopathological examination that constitutes the time of the objective diagnosis is rarely requested.

Endometrial biopsies under hysteroscopy, which allow a reliable result, while limiting the risk of complications, are not within everyone's reach because of the cost or lack of equipment.

\section{Conflicts of Interest}

The authors declare no conflicts of interest regarding the publication of this paper.

\section{References}

[1] Orazi, G., Narducci, F. and Darai, E. (2001) Les Hyperplasies Endométriales. Lettre du Gynécologue, 263, 26-30

[2] Imccluggage, W.G. (2006) My Approach to Interpretation of the Endometrial Biopsies and Curretings. Journal of Clinical Pathology, 59, 801-812. https://doi.org/10.1136/jcp.2005.029702

[3] Ercole, C., Boubli, L. and Charpin, C. (2004) Topathology of Endometrial Hyperplasia. The 24th JTA, 8, 15-36.

[4] Bergeron, C., Nogales, F.F., Masseroli, M., Abeler, V., Duvillard, P., Muller-Holzner, E., et al. (2009) A Multicentric European Study Testing the Reproducibility of the WHO Classification of a Simplified Working Classification for Biopsy and Curettage Specimens. The American Journal of Surgical Pathology, 23, 1102-1108. https://doi.org/10.1097/00000478-199909000-00014

[5] Zaino, R.J., Kauderer, J., Trimble, C.L., Silverberg, S.G., Curtin, J.P., Lim, P.C., et al. (2006) Reproductibility of the Diagnosis of Atypical Endometrialhyperplasia: A Gynecologic Oncology Group Study. Cancer, 106, 804-811

[6] Connell, G.L., Fries, M.H., Zeringue, E. and Mutter, G.L. (2008) Endometrial Precancers: The Benign Endometrial Hyperplasia Sequence and EIN Unpublished Manuscript Mimeol. Department of Harvard Medical School, Boston.

[7] Lefranc, J.P., Truchet, F. and Kamel, R. (2004) Epidemiology of Preneoplastic Endometrial Cells. 9th JTA Fort de France J.

[8] Bergeron, C. (2002) Effets sur l'endomètre des oestrogènes et des antiestrogènes. Gynécologie obstétrique et fertilité [Effect of Oestrogens and Antiestrogens on the Endometrium]. Gynécologie Obstétrique \& Fertilité, 30, 933-937. https://doi.org/10.1016/S1297-9589(02)00486-1

[9] Sakande, B., Lankoande, J., Outtara, T., Ouedraogo, A., Ouedraogo, C., Kone, B., et al. (2006) Les biopsies de l'endomètre au centre hospitalier national Yalgado Ouedraogo de Ouagadougou (Burkina Faso). Médecine d'Afrique Noire, 45, 117-121.

[10] Sanae, Z. (2010) Les Hyperplasies de l'endomètre (à propos de 57cas). Thèse de doctorat en Médecine, Université Sidi Mohamed Ben Abdellah, Fez.

[11] Riberiro, C.T., Rosa-e-Silva, J.C., Silva-de-Sa, M.F., de Rosa-e-Silva, J., Neto, O.B.P. and Nogueira, A.A. (2007) Hysteroscopy as a Standard Procedure for Assessing Endometrial Lesion among Postmenopausal Women. Sao Paulo Medical Journal, 125, 338-242 https://doi.org/10.1590/S1516-31802007000600007

[12] EDS (2012) Direction Nationale de la statistique, Ministère du plan. Enquête 
Démographique et de Santé Guinée 2012. Conakry, 443.

[13] (2012) Guinea Demographic and Health Survey. Conakry, 443.

[14] Brun, J.-L., Descat, E., Boubli, B. and Dallay, D. (2006) Les hyperplasies de l'endomètre [Endometrial Hyperplasia: A Review]. Journal de Gynécologie Obstétrique et Biologie de la Reproduction, 35, 542-550. https://doi.org/10.1016/S0368-2315(06)76444-4

[15] Lansac, J. (2008) Extract from the Updates in Gynaecology and Obstetricshysteroscopy: Results and Limitations in Hyperplasia and Endometrial Cancer.

[16] Dargent, D. (2007) Endometrial Hyperplasia and Polyps. The 28th French Endometrium in Gynaecology Paris-Masson, 265-82.

[17] Catala, L. (2008) Hyperplasie de l'endomètre et stades précoces du cancer de l'endomètre. Reste-T-Il des indications au curetage? Extrait des mises à jour en Gynécologie Obstétrique. CNGOF, TOME XXXII, 239-252.

[18] Dijkhuizen, F.P., Mol, B.W., Brolmann, H.A. and Heintz, A.P. (2000) The Accuracy of Endometrial Sampling in the Diagnosis of Patient with Endometrial Carcinoma and Hyperplasia: A Meta-Analysis. Cancer, 89, 1765-1772.

https://doi.org/10.1002/1097-0142(20001015)89:8<1765::AID-CNCR17>3.0.CO;2-F 